Published in final edited form as:

Brain Res. 2006 December 13; 1125(1): 77-84.

\title{
Changes in neuropeptide $\mathrm{Y}$ immunoreactivity and transcript levels in circadian system structures of the diurnal rodent, the thirteen- lined ground squirrel
}

\author{
Luis Vidal and Nidza Lugo \\ Institute of Neurobiology and Department of Anatomy, University of Puerto Rico, Medical Sciences \\ Campus
}

\begin{abstract}
The intergeniculate leaflet (IGL) and its neuropeptide Y (NPY) projection to the main circadian clock, the suprachiasmatic nucleus ( $\mathrm{SCN}$ ), have been the focus of extensive research conducted, for the most part, on nocturnal rodent species. However, a variety of anatomical and physiological differences between the circadian system of diurnal and nocturnal species have been reported. These differences led us to question whether the role of NPY in the circadian system of the diurnal ground squirrel differs from that in nocturnal rodents. We used semi-quantitative immunohistochemistry to analyze NPY content in SCN terminals of squirrels sacrificed at specific times of the day and compared the data to previous published results from the rat. Additionally, NPY mRNA was quantified using real-time PCR to determine if varying NPY-immunoreactivity (-ir) levels could be the result of changes in peptide transcription. Our results demonstrate that NPY-ir levels in the ground squirrel SCN peak during the middle of the night unlike what is observed in the rat. Cell counts of NPY-ir neurons in the IGL revealed a pattern of variation $6 \mathrm{hr}$ out of phase compared to what was observed in the SCN. NPY mRNA levels showed only one sharp increase in the middle of the night, coinciding with increases in NPY-ir levels observed in the SCN. Differences in the pattern of fluctuation of NPY in the SCN between the rat and squirrel suggest that this peptide may serve distinct roles in the circadian system of diurnal and nocturnal species. Our data provide the first evidence of the relationship between transcript and peptide levels in the circadian system of a diurnal species.
\end{abstract}

\section{Keywords}

Neuropeptide Y; suprachiasmatic nucleus; intergeniculate leaflet; polymerase chain reaction; circadian

\section{Introduction}

The suprachiasmatic nucleus ( $\mathrm{SCN}$ ) of the hypothalamus contains the main circadian clock controlling behavioral and physiological rhythms (Stephan and Zucker, 1972; Moore and Klein, 1974). Retinal ganglion cells project to the SCN via the retinohypothalamic tract (RHT; (Moore and Lenn, 1972; Stephan and Zucker, 1972; Eichler and Moore, 1974; Rusak, 1977; Johnson et al., 1988a; Johnson et al., 1988b), signaling the environmental photoperiod. Retinal ganglion cells also project to the intergeniculate leaflet (IGL) of the thalamus (Hickey and Spear, 1976; Pickard, 1985; Card and Moore, 1989). One class of neurons in the IGL synthesizes neuropeptide Y (NPY; (Card and Moore, 1982; Harrington et al., 1985; Smale et

Corresponding Author: Nidza Lugo, Ph.D, Institute of Neurobiology, 201 Blvd. Del Valle, San Juan, PR 00901; Tel. 787-721-4527; email=nlugo@neuro.upr.ed.

Section: Regulatory Systems 
al., 1991) and projects to the SCN via the geniculohypothalamic tract (GHT; (Card and Moore, 1989; Morin et al., 1992; Morin and Blanchard, 1995).

The role of NPY and the IGL in circadian rhythm modulation has been the focus of extensive research conducted mostly in nocturnal rodents. In the hamster and rat, IGL lesions (1) decrease the amplitude of phase advances induced by brief light pulses (Pickard et al., 1987; Harrington and Rusak, 1988); (2) reduce the normal lengthening of period in constant light (LL; Pickard et al., 1987; Morin and Pace, 2002); (3) slow the rate of re-entrainment (Johnson et al., 1989); (4) abolish or reduce the magnitude of phase shifts induced by non-photic stimuli (Johnson et al., 1988c; Janik and Mrosovsky, 1994; Wickland and Turek, 1994) and (5) eliminate entrainment to a skeleton photoperiod (Edelstein and Amir, 1999). Despite the variety of deleterious effects induced by IGL lesions, the IGL is not necessary for normal circadian expression or entrainment (Johnson et al., 1989).

NPY released from the GHT into the SCN is thought to mediate the foregoing events. Injection of NPY into the SCN, imitating transmitter release from GHT terminals, phase shifts the activity rhythm of hamsters in a time dependent manner (Albers and Ferris, 1984; Huhman and Albers, 1994); and mimics phase shifts elicited by novel non-photic stimuli (Turek and Losee-Olson, 1986; Biello et al., 1994).

NPY content in the rat SCN has been assessed via a variety of methods (e.g., semi-quantitative immunohistochemistry, radioimmunoassay, and enzyme immunoassay) to determine whether NPY levels in the SCN vary over the course of the day. All reports have shown increases in NPY levels both at the beginning and at the end of the light portion of the daily photoperiod (Calzá et al., 1990; Jhanwar-Uniyal et al., 1990) and suggest that NPY in the SCN is under photic regulation. Thus far, none have addressed the question whether the increases in NPY levels in the SCN are the result of increased peptide synthesis in NPY-producing cells of the IGL or the result of selective turnover in the SCN.

There are reports indicating differences between the circadian system of nocturnal and diurnal rodent species, including the number and responsiveness of SCN neurons to light (Meijer et al., 1989; Jiao et al., 1999). There are also differences in the anatomical organization of circadian system structures (Smale et al., 1991). For instance, the laterality of the RHT projection, which is bilateral in most species, is solely to the contralateral SCN in the thirteenlined ground squirrel (Johnson et al., 1988b; Smale et al., 1991; Agarwala et al., 1992).

Differences between the circadian systems of nocturnal and diurnal rodent species, as well as the general lack of information about the role of NPY in diurnal species led us to perform the present investigation in the diurnal thirteen-lined ground squirrel. The studies generated a daily profile of NPY-immunoreactive (-ir) levels in terminals in the SCN as well as counts of NPYir neurons in the IGL. This information was compared to the daily pattern of NPY messenger RNA (mRNA) levels in the IGL. Some of these data have been presented previously in abstract form.

\section{Materials and Methods}

\section{Analysis of NPY content in the SCN at different times}

Animals-Adult thirteen-lined ground squirrels (Spermophilus tridecemlineatus, TLS Research, Bartlet, IL) of both sexes were used in these experiments. Animals were housed under 12/12 LD photoperiod (lights on at 6:00 am E.S.T.). Food and water were available ad libitum. Care was taken to minimize pain and discomfort of all experimental animals. All animal procedures were conducted in accordance with NIH guidelines and approved by the 
Institutional Animal Care and Usage Committee of the University Of Puerto Rico School Of Medicine.

\section{NPY immunocytochemistry}

Twenty-one squirrels were utilized for semi-quantitative NPY analysis in SCN terminals and cell counts in the IGL. Animals were sacrificed at zeitgeber times (ZT) 0, 2, 9, 12, 14, 18, and $22(\mathrm{n}=3 / \mathrm{ZT})$. Animals were given an overdose of sodium pentobarbital (Nembutal, Abbott Laboratories, Carolina, PR; $50 \mathrm{mg} / \mathrm{kg}$ ) and euthanized by intracardial perfusion with $0.1 \mathrm{M}$ phosphate buffer $\mathrm{pH} 7.4$ (PB) followed by a solution of 4\% paraformaldehyde in PB. Sacrifices at ZT0 occurred immediately after light onset, while animals sacrificed at ZT12 were killed immediately after light offset. Animals sacrificed during the dark phase of the photoperiod were euthanized under a dim red safe light, their eyes covered until completion of perfusion to prevent light exposure.

The brains were dissected out and post-fixed for $4 \mathrm{~h}$ in the same fixative and then cryoprotected overnight in a solution of $30 \%$ sucrose in PB at $4^{\circ} \mathrm{C}$. The brains were embedded in a $20 \%$ gelatin solution in PB. Coronal brain sections, $30 \mu \mathrm{m}$ thick, were cut using a sliding microtome with a freezing stage and collected free-floating in PB as a series of six. For each animal, all sections containing the SCN and IGL were selected for immunohistochemistry. Tissue was reacted simultaneously in six-well tissue plates with all sections from only one animal per well. Free-floating brain sections were incubated overnight at $4{ }^{\circ} \mathrm{C}$ in rabbit anti-NPY antiserum (Immunostar, Hudson, WI) diluted 1:4000 in PB with 1\% Triton X-100 and 5\% normal goat serum. Following $3 \times 10$ min washes in $\mathrm{PB}$, sections were incubated in a secondary biotinylated goat anti-rabbit IgG (Jackson Immunoresearch, West Grove, PA) diluted 1:200 in PB, 1\% Triton X-100 and 5\% normal goat serum (Jackson Immunoresearch, West Grove, PA) for $1 \mathrm{~h}$ at room temperature and then processed with the ABC Elite kit (Vector Labs, Burlingame, CA) for $45 \mathrm{~min}$ at room temperature. After pre-incubation in a diaminobenzidine solution (DAB; $0.05 \%$ in $\mathrm{PB}$ for $10 \mathrm{~min}$ at room temperature), sections were reacted in a solution consisting of $0.05 \% \mathrm{DAB}$ and $0.03 \% \mathrm{H}_{2} \mathrm{O}_{2}$ in $\mathrm{PB}$. All sections were reacted simultaneously and left to react for $50 \mathrm{sec}$ in DAB-peroxide solution to control for background staining. Reacted sections were mounted on gel-coated slides, air dried overnight, dehydrated in serial ethanol solutions, cleared with Xylenes and cover slipped with Permount (Fisher Chemicals, Fairlawn, NJ).

\section{Antibody Specificity}

Antibody specificity in NPY immunohistochemical experiments was assessed by omitting the primary antibody and by incubating in primary antisera with an excess of synthetic peptide. Tissue sections were incubated overnight at room temperature in a solution containing NPY antiserum diluted to the working concentration and synthetic porcine NPY at an excess concentration of $10^{-6} \mathrm{M}$ followed by the normal immunohistochemical procedure.

\section{Semi-quantitative analysis of NPY immunocytochemistry}

All brain sections containing the SCN were examined and photographed using a Nikon Eclipse 600 equipped with a Polaroid digital microscope camera. Photomicrographs were processed with the NIH Image program for the PC (downloaded from SCION Corp.,

http://www.scioncorp.com/). Relative optical density (ROD) measurements were taken from a region of interest (ROI) that was established and limited to the SCN for all SCN-containing sections. Background ROD measurements were taken from the dorsal portion of the lateral preoptic area in the same section, where little or no NPY-immunoreactivity was evident, and were equal in size to the SCN ROI measured in each section. Background measurements were subtracted from measurements of NPY-ir levels in the SCN to obtain the final value.

Additionally, measurements of NPY-ir levels in the supraoptic nucleus from the same sections were also taken in the manner previously described. This structure exhibits NPY-ir terminals 
and serves as an internal control for each section examined. ROD measurements were grouped according to ZT's for statistical analysis. Values of ROD represent the mean \pm S.E.M. signal intensity in all SCN-containing sections per ZT sampled. One-Way ANOVA and Tukey's post-hoc tests were performed using the SigmaStat software package (Systat Software, Point Richmond, CA) to determine whether changes in mean ROD measurements across the different ZT's were statistically significant.

\section{Cell profile counts}

All brain sections containing the IGL were examined microscopically and NPY-ir cell bodies were counted using the physical dissector method (Gundersen, 1986; Gundersen et al., 1988a; Gundersen et al., 1988b; Coggeshall and Lekan, 1996). The following procedure was applied to each brain: all IGL-containing sections were arranged in a rostro-caudal series; all sections were then photographed with a digital microscope camera; each photograph was numbered according to its position along the rostro-caudal axis; and cells in the first section of the series were considered acceptable if a cell profile was present in that section, but not in the next section of the series. The same procedure was repeated for all adjacent pairs of sections until the entire IGL was analyzed. Because the sections were $30 \mu \mathrm{m}$ thick, the same cell profile was rarely found in two adjacent sections. SigmaStat was used to perform one-way ANOVA to determine whether differences between cell numbers across different ZT's were significant.

\section{Cloning and sequence analysis of NPY and GAPDH}

Because DNA sequences for ground squirrel NPY and glyceraldehyde-3-phosphate dehydrogenase (GAPDH) were not known, we set out to clone and identify a partial sequence for each gene. Total RNA was isolated from the brain of one adult ground squirrel according to the method of Chomczynski and Sacchi (Chomczynski and Sacchi, 1987), with modifications. Using oligo dT primers, total mRNA was transcribed to complementary (c) DNA with the SupersScript TM first-strand synthesis system for RT-PCR (Invitrogen, Carlsbad, CA). Degenerate primers for NPY and GAPDH were designed by comparing the known amino acid sequences of human, mouse and rat genes and selecting the most conserved regions for each gene. PCR was performed in a $50 \mu \mathrm{L}$ volume with 2.5 units of Platinum ${ }^{\circledR}$ Taq DNA polymerase, $2 \mu \mathrm{L}$ cDNA from first-strand synthesis as a template, and $2 \mu \mathrm{M}$ of the forward and reverse degenerate primers. PCR products for each gene were then resolved in a $10 \%$ polyacrylamide gel. The PCR products were then ligated to the $\mathrm{pCR}^{\circledR} 2.1 \mathrm{TOPO}^{\circledR}$ vector and transformed into TOP10 OneShot ${ }^{\circledR}$ chemically competent $E$. coli cells following the TOPO TA cloning ${ }^{\circledR}$ kit instructions (Invitrogen, Carlsbad, CA). Plasmids containing DNA stretches of the appropriate size were sequenced (DNA Services, Cornell University, Ithaca, NY).

Sequencing results were analyzed using the basic local alignment search tool (BLAST) at the National Institutes of Health website to determine homology to known sequences in a variety of species. On the basis of the sequences obtained (Table 1) the following ground squirrelspecific primers were synthesized (Sigma-Genosys, The Woodlands, TX); 1) for NPY, the forward primer was, 5'-CGGAGGACATGGCCAGATACTACT-3', and the reverse primer was, 5'-TGAATCAGTGTCTCAGGGCTAGA-3', and 2) for GAPDH, the forward primer was 5'-AGCAATGCCTCCTGTACCACCAAC-3', and the reverse primer was, 5'-

GAGGGGCCATCCACAGTCTTCT-3'. Using these primers the expected PCR products were 100 and $134 \mathrm{bp}$ for NPY and GAPDH, respectively (GenBank accession numbers

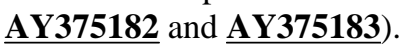

Our cloned sequence spans amino acids 4-36 of the mature peptide as well as 13 amino acids of the C-PON C-terminal peptide of the NPY precursor. The partial cloned sequence (CDS) of 141 bp exhibited $100 \%$ amino acid identity with rhesus, human, mouse, rat and pig NPY sequences. No part of the signal peptide of prepro-NPY was cloned. The ground squirrel 
GAPDH partial CDS of 345 bp exhibited 100\% amino acid identity with woodchuck, a close relative of the ground squirrel, rat and mouse GAPDH.

Specific primers and cDNA transcribed from total brain mRNA were used to test and optimize the PCR reaction prior to the beginning of quantification. The optimal annealing temperatures chosen for the final experiments were $61^{\circ} \mathrm{C}$ and $66^{\circ} \mathrm{C}$ for NPY and GAPDH, respectively. A melting peak analysis performed following the 40 amplification cycles revealed the melting temperature $\left(\mathrm{T}_{\mathrm{m}}\right)$ for NPY product was $81.3 \pm 0.01$ (mean \pm S.E.) ${ }^{\circ} \mathrm{C}$ and $82.9 \pm 0.01{ }^{\circ} \mathrm{C}$ for GAPDH. No primer dimer formation was detected in the melt peak analysis (not shown).

\section{RNA Isolation for NPY quantification}

Eighteen squirrels were used to quantify NPY mRNA at various ZT's. Animals were sacrificed at ZT's $8,10,12,18,20$, and $22(\mathrm{~N}=3 / \mathrm{ZT})$ by giving an overdose of Nembutal $(75 \mathrm{mg} / \mathrm{kg})$ followed by decapitation. Animals sacrificed during the dark phase of the day were handled using a dim red safe light. Squirrels sacrificed at ZT12 were euthanized immediately after lights off. The brains were quickly removed from the skull and placed in a sterile glass petri dish precleaned with RNaseZap ${ }^{\circledR}$ (Ambion, Austin, TX) to prevent RNase contamination. A brain slice of approximately $3.5 \mathrm{~mm}$ thick that contained the diencephalon was cut using a sterile blade. A $2 \mathrm{~mm}$ diameter sterile hole punch was used to dissect the IGL on both sides of the brain. Bilateral IGL punches were immediately weighed and immersed in RNAlater ${ }^{\mathrm{TM}}$ (Ambion, Austin, TX) and stored at $-20^{\circ} \mathrm{C}$ until ready to use. Bilateral IGL tissue punches weighed between $20-25 \mathrm{mg}$. These were placed in a sterile, nuclease-free microcentrifuge tube with 10 volumes of RNAwiz ${ }^{\mathrm{TM}}$ (Ambion, Austin, TX) RNA isolation reagent per volume of tissue. The tissue was homogenized in RNAwiz ${ }^{\mathrm{TM}}$ using a tissue pellet pestle until completely disrupted. RNA extraction was completed according to the manufacturer's instructions. Following extraction, RNA yield was assessed using the RiboGreen ${ }^{\circledR}$ (Molecular Probes, Eugene, OR) fluorescent nucleic acid stain kit with a filter fluorometer.

\section{Reverse Transcription and Real Time Quantitative PCR}

Total RNA isolated from bilateral IGL's of individual animals were used for reverse transcription (2 IGL punches/brain; 3 brains/ZT). First strand cDNA templates were prepared with oligo dT primers from $1 \mu \mathrm{g}$ of RNA using the SuperScript ${ }^{\mathrm{TM}}$ first-strand synthesis system (Invitrogen, Carlsbad, CA). Real-time PCR was performed using a Smart Cycler ${ }^{\circledR}$ system according to the manufacturer's instructions. Reactions were performed in a $25 \mu \mathrm{L}$ volume with $2 \mu \mathrm{M}$ primers and $10 \%$ cDNA. Nucleotides, $\mathrm{MgCl}_{2}$, HotStarTaq ${ }^{\mathrm{TM}}$ DNA polymerase, buffer, and SYBR Green I were included in the QuantiTect ${ }^{\mathrm{TM}} \mathrm{SYBR}^{\circledR}$ Green PCR kit mix (Qiagen, Valencia, CA). Quantitative RT-PCR was performed by monitoring the increase in fluorescence of the SYBR-green dye. The NPY levels were normalized to GAPDH levels. NPY mRNA levels are expressed as the mean ratio of NPY/GAPDH at all ZT's sampled. Each RT-PCR quantification experiment was performed in triplicate using samples from two independently generated cDNA templates for each ZT tested. To confirm amplification specificity, the PCR products from each primer pair were subjected to a melting curve analysis to verify that the product had a single melting peak, followed by polyacrylamide gel electrophoresis. Statistical significance was determined by one-way ANOVA using SigmaStat.

\section{Results \\ NPY in the SCN and IGL}

Control sections through the SCN and IGL treated with antiserum and synthetic peptide showed no NPY-ir SCN terminals or labeled NPY-ir cells. Control sections in which the primary antibody was omitted yielded identical results (data not shown). NPY-ir cell bodies are present in the IGL (Fig. 1A) and are mostly oval-or spindle-shaped with a few triangular cells also 
present (Fig. 1A'). No morphological type is restricted to any specific region of the IGL; rather, all morphological types and sizes appear evenly distributed throughout the nucleus. At rostral levels, NPY-ir cells are few and usually located close to the optic tract. The mid portion of the IGL contains numerous neurons which form a band of cells that expand medially, wedged between the dorsal lateral geniculate nucleus (DLG) and ventral lateral geniculate nucleus (VLG), and bordered laterally by the optic tract. Caudally, as the VLG expands and the IGL disappears, fewer NPY-ir neurons are evident. NPY-ir cells are also found in the parvicellular segment and in the external magnocellular lamina of the VLG, and a few cells are seen in the optic tract.

The NPY-ir terminal field is seen throughout the rostro-caudal extent of the SCN. It is not restricted to a specific sub-region of the SCN, but rather spreads uniformly throughout the nucleus. At the most rostral levels of the nucleus, the terminal field occupies a small, round area dorsal to the optic chiasm and lateral to the third ventricle. As the nucleus expands caudally the terminal field appears oval in shape (Fig. 2C). More caudally, the NPY-ir terminal field is elongated, its fibers extending vertically along the basal third ventricle. NPY-ir cell bodies are not seen in the ground squirrel SCN.

\section{Temporal profile of NPY-ir levels in the SCN}

A daily variation in the optical density of NPY-ir fibers in the SCN was readily observed. Under a 12/12 LD photoperiod, visible NPY-ir levels in the SCN varied substantially across the day (Fig. 2A-D). Optical density quantification revealed that the changes were systematic, with a unimodal rhythmic pattern (Fig. 3). NPY-ir levels were low throughout the day and reached their lowest levels at ZT9. An increase in NPY-ir levels was observed at the offset of lights, i.e. ZT12. Levels continued to increase and peaked six hours after "lights off" at ZT18. This peak was followed by a slight decrease at ZT22 and a marked decrease by ZT0. A One Way ANOVA revealed that there was an effect of $Z T$ on NPY-ir levels $(P=0.020)$. A significant difference was observed when levels at ZT9 were compared to levels at ZT18 (Tukey's posthoc, $\mathrm{p}<0.05)$.

Control measurements taken in the supraoptic nucleus revealed that NPY-ir optical density values remained constant at all time points sampled (mean $=29.8 \mathrm{SEM} \pm 1.4 ; \mathrm{P}>0.05$; One Way ANOVA). Additionally, background measurements taken from the dorsal portion of the lateral preoptic area did not vary significantly throughout the day and their optical density values were lower than those observed in the SCN.

\section{Cell counts in the IGL at various ZT's}

Cell counts in the IGL revealed significant differences in the mean number of countable NPYir neurons/IGL histological section in animals sacrificed at different ZT's (Kruskal-Wallis One Way Analysis of Variance, $\mathrm{P}=<0.001$; Fig. 3A,C). A pairwise multiple comparison test revealed significant differences when comparing cell counts at ZTs 18, 22, and 0 versus ZT's 2, 9, 12 and 14 (Dunn's post-hoc, $\mathrm{p}<0.05$ ). The largest numbers of NPY-ir neurons were seen in animals sacrificed at ZT0 and during the latter part of the night at ZT18 and ZT22. Counts during the light portion of the day remained relatively constant; but were approximately half, or less than half, the number observed during the night.

\section{Changes in NPY mRNA in the IGL at specific ZT's}

NPY mRNA levels in the IGL were normalized to levels of the housekeeping gene GAPDH. No significant variation was observed in mean cycle times $\left(\mathrm{C}_{\mathrm{T}}\right)$ for GAPDH at the different times sampled (Kruskall-Wallis ANOVA, $\mathrm{P}=0.052$; mean 17.1 SEM \pm 0.1 ; Fig. 4). Levels of NPY mRNA were relatively low during the late afternoon, with a trough occurring at ZT12. Transcript levels reached a unimodal peak six hours after lights off at ZT18 and then dropped 
rapidly during the dark phase. Following normalization to IGL GAPDH content, KruskalWallis One Way Analysis of Variance indicated statistically significant variation in NPY mRNA levels across the day $(\mathrm{P}=<0.001)$. Significant differences were observed when comparing levels at ZT's 12 and 20 versus ZT18 and comparing levels at ZT22 versus ZT12 (Dunn's post-hoc, $\mathrm{p}<0.05$ ). The mock PCR run in which untranscribed RNA was used, yielded no bands of amplified product, indicating the absence of genomic DNA contamination.

\section{Discussion}

\section{Distribution of NPY in the circadian system}

Anatomical comparisons of neurotransmitter distribution in the circadian systems of nocturnal and diurnal rodents have been reported. Our findings agree with previous reports which indicate that NPY-ir terminals are present throughout the entire extent of the SCN while NPY-ir cell bodies and terminals are present in the IGL of the ground squirrel (Reuss et al., 1989; Smale et al., 1991; Agarwala et al., 1992). We also observed NPY-ir cells in the external magnocellular lamina of the VLG; a finding that agrees with that of Agarwala et al., (Agarwala et al., 1992). Unpublished results from our lab suggest that these cells project to the SCN and can be considered as part of the IGL. There were rarely any NPY-ir cells present in the internal magnocellular lamina or dorsal cap of the VLG.

\section{Daily profile of NPY-ir levels in the SCN and cell numbers in the IGL}

These observations are the first to report a rhythm of NPY-ir in terminals in the SCN and cells of the IGL in a diurnal species. An increase in NPY-ir levels in the SCN began at ZT12, and reached maximal levels at ZT18. The data at these times do not agree with prior reports in rats (Calzá et al., 1990; Shinohara et al., 1993b), which state that NPY content in the rat SCN peaks just before the onset of darkness. Additionally, our results demonstrate that the density of NPYir is somewhat diminished at ZT22 and continues to decrease to ZT0. Although NPY-ir levels are higher at ZT's 22 and 0, compared to trough, it is apparent that levels are on the decline. This differs from previous reports in rat that demonstrate a second peak in NPY content in the rat SCN at the onset of lights (Jhanwar-Uniyal et al., 1990) or two hours after the onset of lights (Calzá et al., 1990; Shinohara et al., 1993b). The stability of the background measurements across sections from different animals and the lack of any daily variation in NPY-ir measurements in the supraoptic nucleus lend strong support to our conclusions.

In the IGL, the daily variation in the number of NPY-ir cell counts was different from the daily pattern of NPY-ir levels observed in terminals of the SCN. NPY-ir levels in terminals of the SCN peaked at ZT0, approximately $6 \mathrm{hr}$ before the peak of visible cells in the IGL. Despite both rhythms being out of phase by $6 \mathrm{hr}$, NPY-ir levels in the SCN and cell counts were lowest during the light portion of the day.

Increases in NPY content in the SCN of rats near or at the times of photic transitions have led to the conclusion that NPY serves to convey information on photic transitions to the pacemaker (Calzá et al., 1990; Jhanwar-Uniyal et al., 1990; Shinohara et al., 1993b). Furthermore, rats presented with a 5 min light pulse at ZT0, to mimic the sudden dusk to dawn transition, exhibit increases in NPY content in the SCN (Shinohara et al., 1993a). The ground squirrel NPY rhythm in the SCN however, is different from the rat, exhibiting only a single peak at ZT18, suggesting that NPY plays distinct roles in the circadian system of these species. In the diurnal Nile rat, Arvicanthis, novel wheel exposure during the daytime induces increased Fos expression in NPY cells of the IGL (Smale et al., 2001). In nocturnal rodents, while novel wheel exposure is able to elicit phase shifts that are highly dependent on NPY, (Johnson et al., 1988c; Janik and Mrosovsky, 1994; Wickland and Turek, 1994) Fos induction in the IGL in response to such stimulus is phase independent (Mikkelsen et al., 1998). It is feasible to suggest 
that daytime activity bouts may also activate NPY cells in the ground squirrel IGL which may lead to an increase in peptide transport followed by subsequent release from SCN terminals. This may explain the low levels of NPY-ir observed during the daytime in the SCN. Accumulation of NPY in terminals of the SCN observed at night may reflect slow peptide turnover due to decreased activity. Increases in NPY-ir cell counts during the night and peaking at ZT0 may be the result of peptide accumulation for eventual daytime release.

\section{Changes in NPY mRNA levels in the IGL at specific ZT's}

The results from measurements of NPY mRNA levels in the IGL reveal apparent similarities between transcript levels and NPY-ir in the SCN at various times sampled. First, transcript levels reach a peak during the middle of the night, similar to NPY-ir in the SCN at approximately the same times. Second, the data also indicate that NPY mRNA is expressed at relatively low levels during the day. This again coincides with what is observed for NPY-ir terminals in the SCN. However, despite the similarity of both rhythms, it is unlikely that the increase in transcript levels is directly responsible for the simultaneous increase in NPY-ir levels observed in the SCN. There is likely to be some lag detecting NPY in the SCN following transcription as a result of translation and peptide transport.

A comparison of the daily profiles of NPY-ir cell counts and NPY mRNA levels in the IGL illustrates that the number of visible cells is maximal at ZT0 and is preceded by a peak in transcript levels by approximately $6 \mathrm{hr}$. While the transcript and cell count peaks are offset by $6 \mathrm{hr}$, it is evident that there are elevated cell numbers in the IGL during the middle and late night. Thus it appears that it takes several hours for NPY peptide synthesis to proceed before levels rise sufficiently to detect NPY by immunohistochemistry in some cells. It is also evident that cells numbers are still elevated after transcription levels drop, suggesting that once the peptide is synthesized there is an additional lag in the time it takes for NPY to be degraded or transported elsewhere for release. Both transcription levels and cell numbers are relatively low during the late portion of the day and at the offset of lights.

To date, it is not known if this rhythm would persist in squirrels housed under constant light or dark conditions. If a similar profile of NPY mRNA is not detected under constant conditions, such a result would suggest that, much like the protein rhythm in rats (Shinohara et al., 1993b), peptide synthesis is regulated by the photoperiod. However, persistence of the rhythm in constant conditions would indicate that a specific IGL function is under SCN regulation.

Our data are the first to report a rhythm of NPY-ir and mRNA in the circadian system of a diurnal rodent housed in a 12/12 LD cycle. Additionally, the results presented in this report contribute to the emerging knowledge base of comparative studies analyzing the circadian system of diurnal and nocturnal species. Despite similarities in the anatomical organization of the NPY system between many diurnal and nocturnal rodent species, our data and previous reports suggest that the IGL and its NPY projection to the SCN play distinct roles. Further research on the topic is merited in order to discern the modulatory influence exerted by the IGL and NPY on circadian rhythms in diurnal species and compare it to the vast literature on the topic in nocturnal species.

\section{Acknowledgements}

The authors would like to thank Dr. L. Morin for his insightful and thorough review of the manuscript. We would also like to thank Mrs. Vannessa Cartagena for technical assistance.

\section{References}

Agarwala S, May JG III, Moore JK, Petry HM. Immunohistochemical organization of the ventral lateral geniculate nucleus in the ground squirrel. J Comp Neurol 1992;318:255-266. [PubMed: 1374767] 
Albers HE, Ferris CF. Neuropeptide Y: role in light-dark entrainment of hamster circadian rhythms. Neurosci Lett 1984;50:163-168. [PubMed: 6548555]

Biello SM, Janik D, Mrosovsky N. Neuropeptide Y and behaviorally induced phase shifts. Neuroscience 1994;62:273-279. [PubMed: 7816205]

Calzá L, Giardino L, Zanni M, Velardo A, Parchi P, Marrama P. Daily changes of neuropeptide Y-like immunoreactivity in the suprachiasmatic nucleus of the rat. Regul Pept 1990;27:127-137. [PubMed: 2408111]

Card JP, Moore RY. Organization of lateral geniculate-hypothalamic connections in the rat. J Comp Neurol 1989;284:135-147. [PubMed: 2754028]

Card JP, Moore RY. Ventral lateral geniculate nucleus efferents to the rat suprachiasmatic nucleus exhibit avian pancreatic polypeptide-like immunoreactivity. J Comp Neurol 1982;206:390-396. [PubMed: 6178763]

Chomczynski P, Sacchi N. Single-step method of RNA isolation by acid guanidinium thiocyanatephenol-chloroform extraction. Anal Biochem 1987;162:156-159. [PubMed: 2440339]

Coggeshall RE, Lekan HA. Methods for determining numbers of cells and synapses: A case for more uniform standards of review. J Comp Neurol 1996;364:6-15. [PubMed: 8789272]

Edelstein K, Amir S. The role of the intergeniculate leaflet in entrainment of circadian rhythms to a skeleton photoperiod. J Neurosci 1999;19:372-380. [PubMed: 9870966]

Eichler VB, Moore RY. The primary and accessory optic systems in the golden hamster, Mesocricetus auratus. Acta Anatomica 1974;89:359-371. [PubMed: 4611127]

Gundersen HJ. Stereology of arbitrary particles. A review of unbiased number and size estimators and the presentation of some new ones, in memory of William R Thompson. J Microsc 1986;143 ( Pt 1): 3-45. [PubMed: 3761363]

Gundersen HJ, Bagger P, Bendtsen TF, Evans SM, Korbo L, Marcussen N, Moller A, Nielsen K, Nyengaard JR, Pakkenberg B. The new stereological tools: disector, fractionator, nucleator and point sampled intercepts and their use in pathological research and diagnosis. APMIS 1988a;96:857-881. [PubMed: 3056461]

Gundersen HJ, Bendtsen TF, Korbo L, Marcussen N, Moller A, Nielsen K, Nyengaard JR, Pakkenberg B, Sorensen FB, Vesterby A. Some new, simple and efficient stereological methods and their use in pathological research and diagnosis. APMIS 1988b;96:379-394. [PubMed: 3288247]

Harrington ME, Nance DM, Rusak B. Neuropeptide Y immunoreactivity in the hamster geniculosuprachiasmatic tract. Brain Res Bull 1985;15:465-472. [PubMed: 3840718]

Harrington ME, Rusak B. Ablation of the geniculo-hypothalamic tract alters circadian activity rhythms of hamsters housed under constant light. Physiol Behav 1988;42:183-189. [PubMed: 3368539]

Hickey TL, Spear PD. Retinogeniculate projections in hooded and albino rats: an autoradiographic study. Exp Brain Res 1976;24:523-529. [PubMed: 1253865]

Huhman KL, Albers HE. Neuropeptide Y microinjected into the suprachiasmatic region phase shifts circadian rhythms in constant darkness. Peptides 1994;15:1475-1478. [PubMed: 7700850]

Janik D, Mrosovsky N. Intergeniculate leaflet lesions and behaviorally-induced shifts of circadian rhythms. Brain Res 1994;651:174-182. [PubMed: 7922565]

Jhanwar-Uniyal M, Beck B, Burlet C, Leibowitz SF. Diurnal rhythm of neuropeptide Y-like immunoreactivity in the suprachiasmatic, arcuate and paraventricular nuclei and other hypothalamic sites. Brain Res 1990;536:331-334. [PubMed: 2085760]

Jiao YY, Lee TM, Rusak B. Photic responses of suprachiasmatic area neurons in diurnal degus (Octodon degus) and nocturnal rats (Rattus norvegicus). Brain Res 1999;817:93-103. [PubMed: 9889333]

Johnson RF, Moore RY, Morin LP. Loss of entrainment and anatomical plasticity after lesions of the hamster retinohypothalamic tract. Brain Res 1988a;460:297-313. [PubMed: 2465060]

Johnson RF, Moore RY, Morin LP. Lateral geniculate lesions alter activity rhythms in the hamster. Brain Res Bull 1989;22:411-422. [PubMed: 2650808]

Johnson RF, Morin LP, Moore RY. Retinohypothalamic projections in the hamster and rat demonstrated using cholera toxin. Brain Res 1988b;462:301-312. [PubMed: 3191391]

Johnson RF, Smale L, Moore RY, Morin LP. Lateral geniculate lesions block circadian phase shift responses to a benzodiazepine. Proc Natl Acad Sci USA 1988c;85:5301-5304. [PubMed: 3293053] 
Meijer JH, Rusak B, Harrington ME. Photically responsive neurons in the hypothalamus of a diurnal ground squirrel. Brain Res 1989;501:315-323. [PubMed: 2479451]

Mikkelsen JD, Vrang N, Mrosovsky N. Expression of Fos in the circadian system following nonphotic stimulation. Brain Res Bull 1998;47:367-376. [PubMed: 9886789]

Moore RY, Klein DC. Visual pathways and the central neural control of a circadian rhythm in pineal serotonin N-acetyltransferase activity. Brain Res 1974;71:17-33. [PubMed: 4595289]

Moore RY, Lenn NJ. A retinohypothalamic projection in the rat. J Comp Neurol 1972;146:1-14. [PubMed: 4116104]

Morin LP, Blanchard JH. Organization of the hamster intergeniculate leaflet: NPY and ENK projections to the suprachiasmatic nucleus, intergeniculate leaflet and posterior limitans nucleus. Vis Neurosci 1995;12:57-67. [PubMed: 7536441]

Morin LP, Blanchard JH, Moore RY. Intergeniculate leaflet and suprachiasmatic nucleus organization and connections in the hamster. Vis Neurosci 1992;8:219-230. [PubMed: 1372173]

Morin LP, Pace L. The intergeniculate leaflet, but not the visual midbrain, mediates hamster circadian rhythm response to constant light. J Biol Rhythms 2002;17:217-226. [PubMed: 12054193]

Pickard GE. Bifurcating axons of retinal ganglion cells terminate in the hypothalamic suprachiasmatic nucleus and the intergeniculate leaflet of the thalamus. Neurosci Lett 1985;55:211-217. [PubMed: 4000547]

Pickard GE, Ralph MR, Menaker M. The intergeniculate leaflet partially mediates effects of light on circadian rhythms. J Biol Rhythms 1987;2:35-56. [PubMed: 2979650]

Reuss S, Hurlbut EC, Speh JC, Moore RY. Immunohistochemical evidence for the presence of neuropeptides in the hypothalamic suprachiasmatic nucleus of ground squirrels. Anat Rec 1989;225:341-346. [PubMed: 2589647]

Rusak B. Involvement of the primary optic tracts in the mediation of light effects on hamster circadian rhythms. J Comp Physiol 1977;118:165-172.

Shinohara K, Tominaga K, Fukuhara C, Otori Y, Inouye SIT. Processing of photic information within the intergeniculate leaflet of the lateral geniculate body: Assessed by neuropeptide $Y$ immunoreactivity in the suprachiasmatic nucleus of rats. Neuroscience 1993a;56:813-822. [PubMed: 8284035]

Shinohara K, Tominaga K, Isobe Y, Inouye S-IT. Photic regulation of peptides located in the ventrolateral subdivision of the suprachiasmatic nucleus of the rat: Daily variations of vasoactive intestinal polypeptide, gastrin-releasing peptide, and neuropeptide Y. J Neurosci 1993b;13:793-800. [PubMed: 8426236]

Smale L, Blanchard JH, Moore RY, Morin LP. Immunocytochemical characterization of the suprachiasmatic nucleus and the intergeniculate leaflet in the diurnal ground squirrel, Spermophilus lateralis. Brain Res 1991;563:77-86. [PubMed: 1723927]

Smale L, Mcelhinny T, Nixon J, Gubik B, Rose S. Patterns of wheel running are related to Fos expression in neuropeptide-Y-containing neurons in the intergeniculate leaflet of Arvicanthis niloticus. J Biol Rhythms 2001;16:163-172. [PubMed: 11302558]

Stephan FK, Zucker I. Circadian rhythms in drinking behavior and locomotor activity of rats are eliminated by hypothalamic lesions. Proc Natl Acad Sci USA 1972;69:1583-1586. [PubMed: 4556464]

Turek FW, Losee-Olson S. A benzodiazepine used in the treatment of insomnia phase-shifts the mammalian circadian clock. Nature 1986;321:167-168. [PubMed: 3703016]

Wickland C, Turek FW. Lesions of the thalamic intergeniculate leaflet block activity-induced phase shifts in the circadian activity rhythm of the golden hamster. Brain Res 1994;660:293-300. [PubMed: 7820698] 


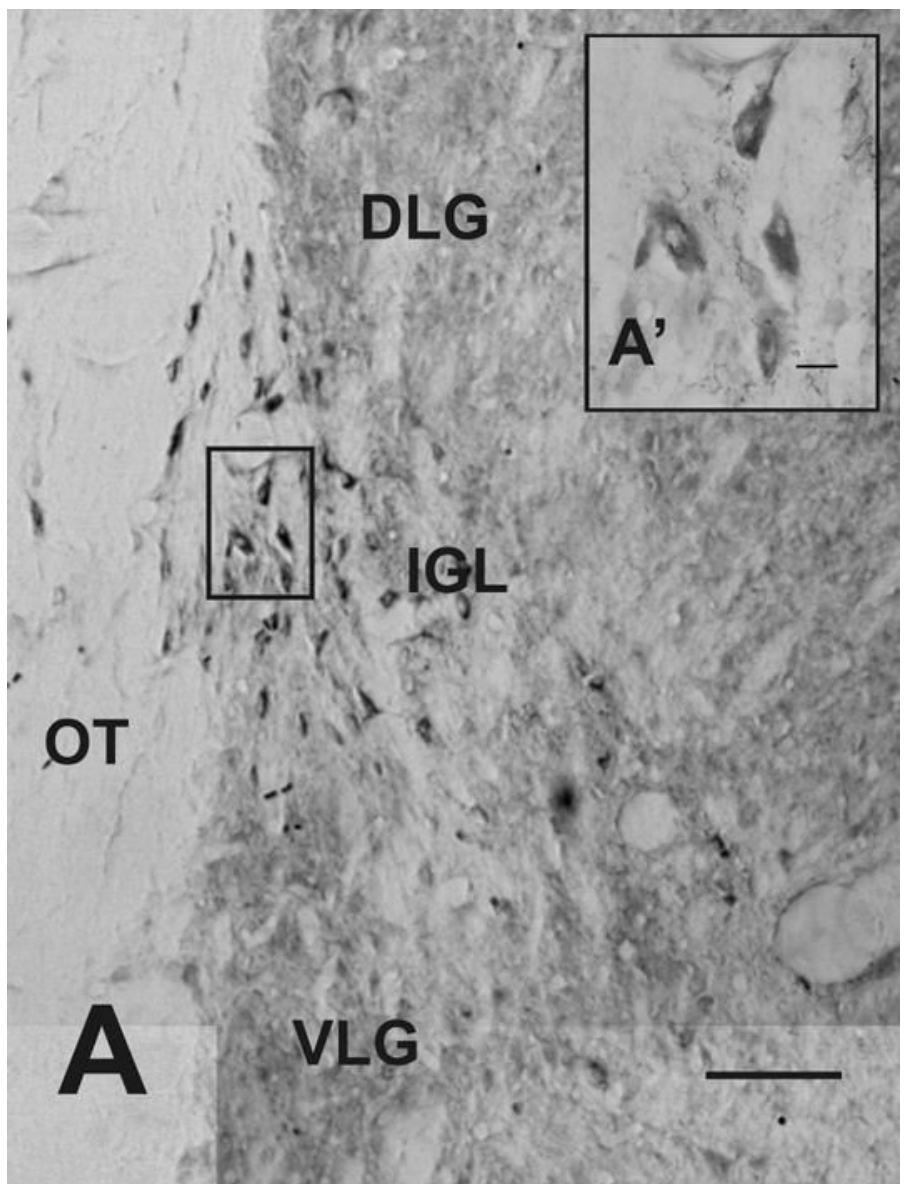

Fig. 1.

A. Coronal section through the ground squirrel mid-IGL illustrating the location of NPY-ir cells. A'. Higher magnification of NPY-ir cells in (A) showing the morphology of the cells in more detail. III-Third Ventricle; DLG - Dorsal Lateral Geniculate nucleus, VLG - Ventral Lateral Geniculate nucleus, OT - Optic Tract. Scale bar in A= $100 \mu \mathrm{m}$; Scale bar in $\mathbf{A}^{\prime}=$ $20 \mu \mathrm{m}$. 

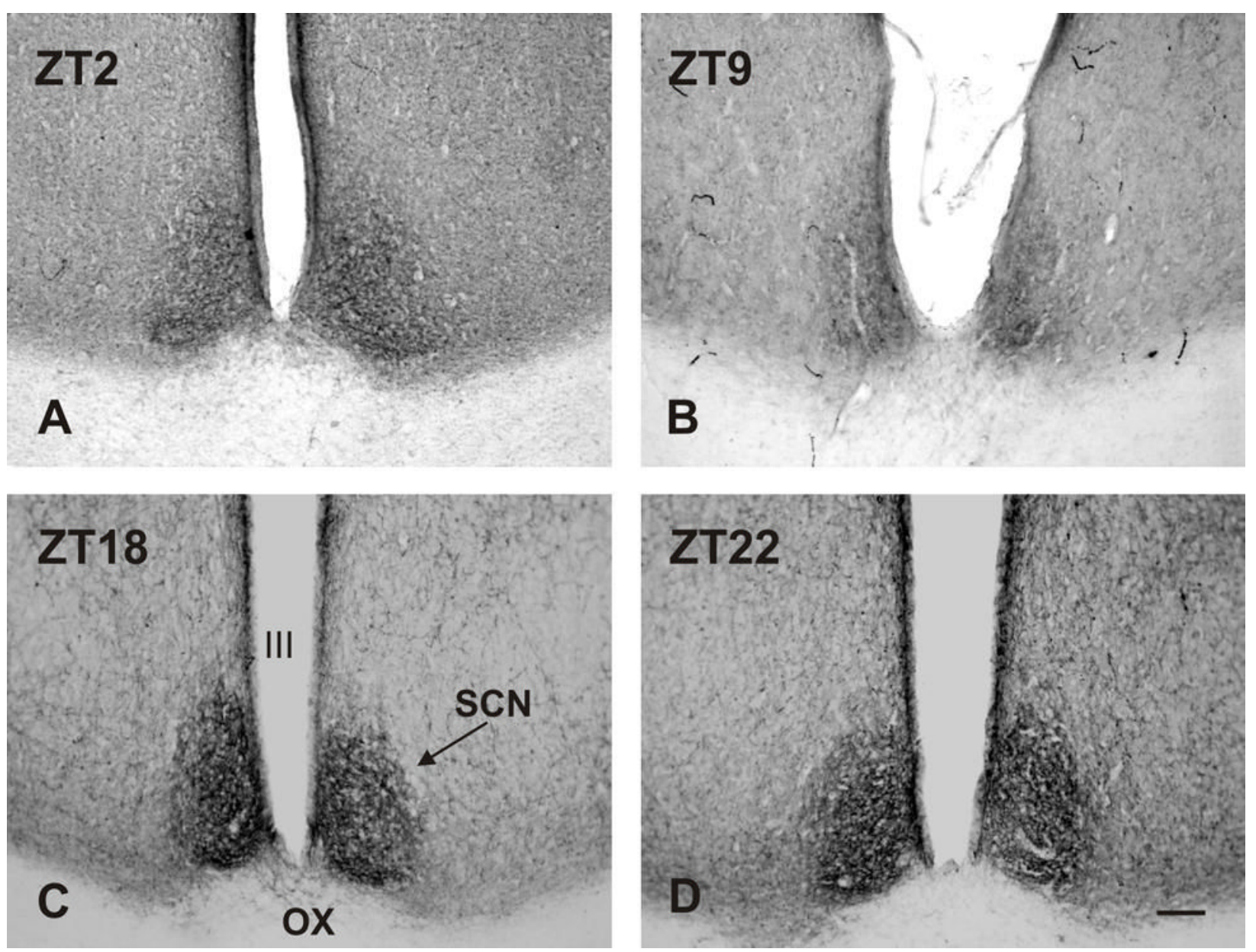

Fig. 2.

A-D. Coronal photomicrographs through the hypothalamus showing NPY-ir terminals in the SCN of animals sacrificed at various ZT's. Although all sections correspond to approximately the mid portion of the SCN there is variation in the shape of the SCN and the third ventricle (III). Note variations in the intensity of NPY-ir terminals between animals. C. NPY-ir terminals delineate the SCN. OX-Optic Chiasm. Scale bar $=100 \mu \mathrm{m}$. 


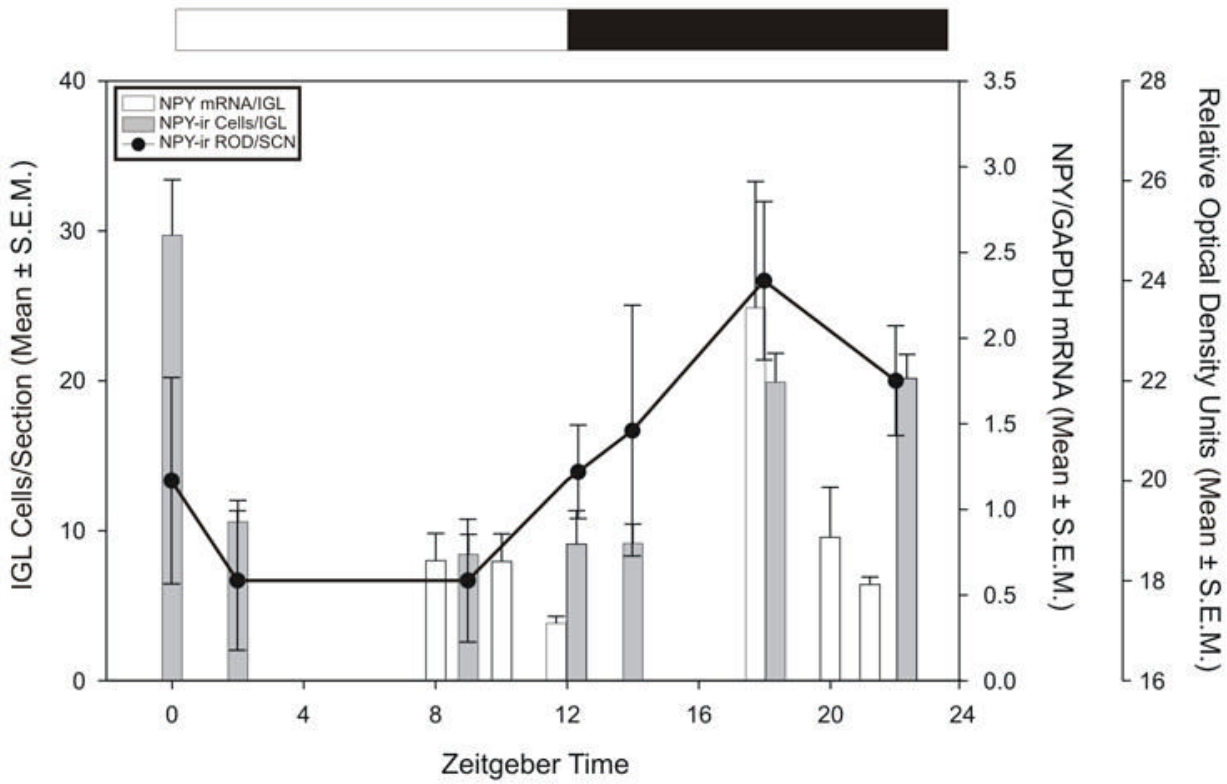

Fig. 3.

Summary plot for all experiments discussed. Line plot $=$ NPY-ir in the SCN (mean ROD Units \pm SEM); Grey bar histogram $=$ NPY-ir cells in the IGL (mean \pm SEM). White bar histogram $=$ normalized NPY mRNA levels in the IGL $($ mean \pm SEM). Bar on top denotes the photic conditions throughout the day. 


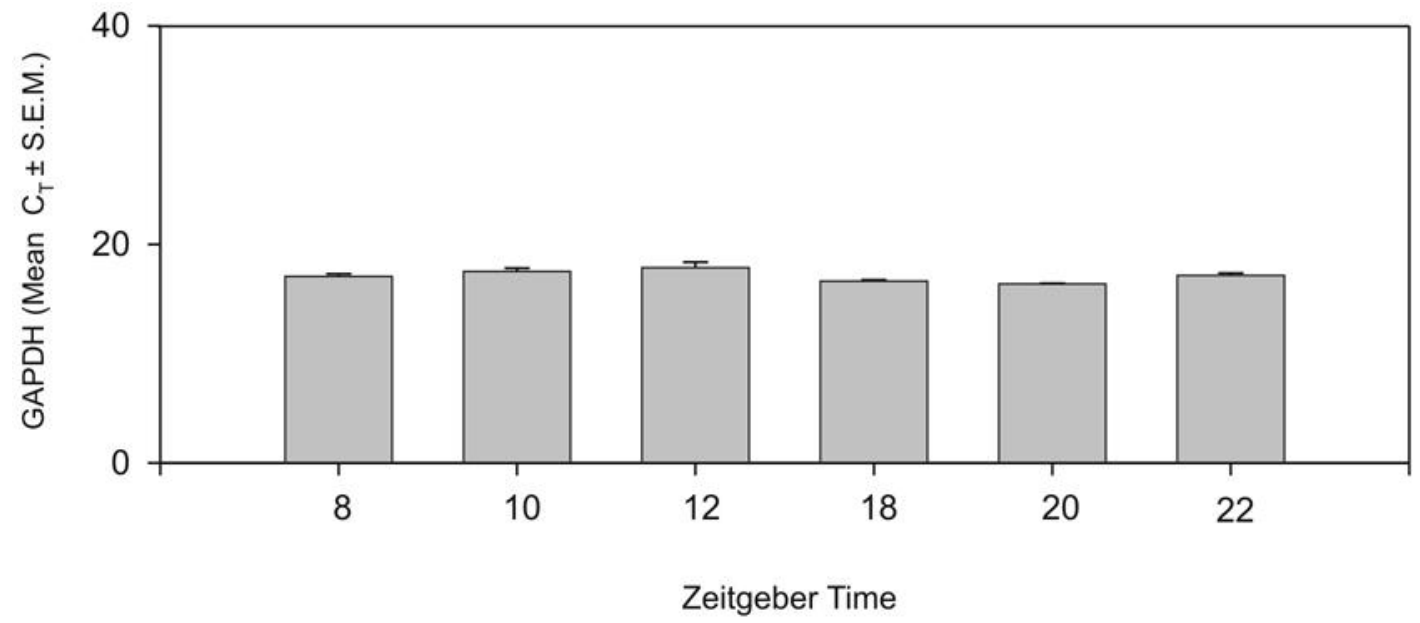

Fig. 4.

Mean Cycle Time $\left(\mathrm{C}_{\mathrm{T}}\right)$ of GAPDH at different times sampled. GAPDH $\mathrm{C}_{\mathrm{T}}$ 's remained quite stable at the different times sampled. 


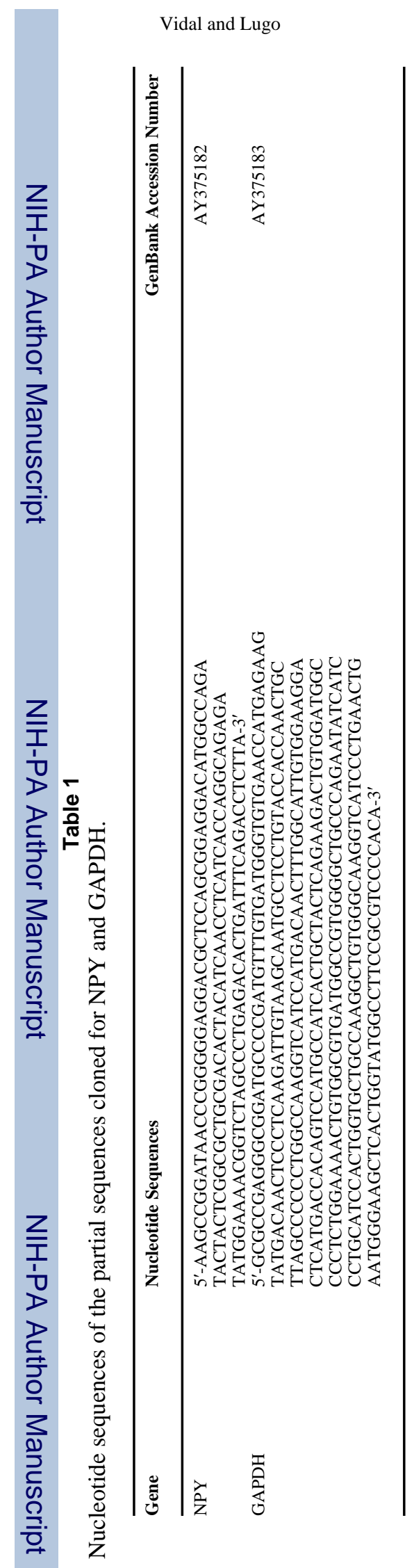

Page 15

Brain Res. Author manuscript; available in PMC 2007 December 13. 